\title{
Renascimento africano no século XXI? Desafios pós-coloniais e as reflexões sobre a África nas Relações Internacionais
}

African renaissance in the 21st century? Post-colonial challenges and reflections on Africa in International Relations

¿Renacimiento africano em el siglo xxi? Desafíos post-coloniales y reflexiones sobre África en las Relaciones Internacionales

Joyce Amâncio de Aquino Alves ${ }^{1}$

DOI: 10.5752/P.1809-6182.2019v16.n2.p7

Recebido em: 29 de março de 2019 Aprovado em:25 de maio de 2019

\begin{abstract}
Resumo
O conceito de Renascimento Africano é visto como uma concepção que define a inserção africana na politica internacional no século XXI. Consideramos que o Renascimento Africano, exposto por alguns analistas como conceito indissociável do crescimento econômico, mostra-se insuficiente para a compreensão dos velhos desafios, como a integração e o desenvolvimento. Palavras-chaves: África. Relaçóes Internacionais. Renascimento Africano.
\end{abstract}

\begin{abstract}
The concept of the African Renaissance as conception that defines the African insertion in international politics in the 21st century. We consider that the African Renaissance, exposed by some analysts as an inseparable concept of economic growth, is insufficient to understand the old challenges, such as integration and development.
\end{abstract}

Keywords: Africa. International Relations. African Renaissance.

\section{Resumen}

El concepto del Renacimiento africano se ve como una concepción que define la inserción africana en la politica internacional en el siglo XXI. Consideramos que el Renacimiento Africano, que algunos analistas han expuesto como un concepto inseparable del crecimiento económico, es insuficiente para comprender viejos desafios como la integración y el desarrollo. Palabras clave: África. Relaciones Internacionales. Renacimiento Africano

\footnotetext{
1 Professora do Instituto de Humanidades e Letras da Universidade da Integraçáo Internacional da Lusofonia Afro-Brasileira- Campus Malês, Brasil. Pesquisadora do Grupo de Pesquisa Órbita: Observatório de Relaçóes Internacionais. Doutora em Sociologia pela Universidade Federal de Pernambuco (2018), Mestra em Ciências Sociais pela Universidade Federal de Campina Grande (2013) e Graduada em Relaçôes Internacionais pela Universidade Estadual da Paraíba (2011). Salvador- Ba/ Brasil. ORCID: 0000-0003-3785-2648.
} 


\section{Introdução}

O continente africano é permeado por desafios no contexto de sua descolonização, como as tensões produzidas desde as fronteiras artificialmente criadas, bem como a organização política dos novos Estados que levassem a cabo a emancipação completa do continente (MBOKOLO, 2011).

Alguns debates teóricos sobre a inserção da África no cenário internacional no século XXI esboçam que há uma transição positiva para os Estados africanos e discutem sobre o papel da África a partir do contexto de multilateralismo. De acordo com Saraiva (2008), alguns elementos que reforçam essa hipótese são: o avanço gradual dos processos de democratização dos Estados, a performance satisfatória associada ao crescimento econômico e certa elevação de confiança política das elites, uma vez que a África vem sendo prioridade de empréstimos do Banco Mundial.

Há intelectuais que apontam os dilemas sobre o desenvolvimento africano, como Macuane (2005), Hugon (2010) e Edmondson (2011), que discutem em seus argumentos os paradoxos do desenvolvimento africano atrelados às demandas externas do Banco Mundial e Fundo Monetário Internacional (FMI), frente aos desafios dos sistemas nacionais e internacionais da África. Para Macuane (2005), as estratégias de desenvolvimento, apesar de terem sido seguidas da sua componente social, não conseguiram resolver os problemas de endividamento e desenvolvimento no continente.

Nesse sentido, para tratarmos dos desafios após a descolonização que se refletem no contexto da contemporaneidade, o artigo explana que muitas das ideias que centralizam a compreensão da inserção internacional da África trazem a necessidade do aprofundamento de alguns conceitos, tais como o conceito de "Renascimento Africano". Essa conceituação traz o seu significado para a responsa- bilização das elites africanas em torno de transformações, com questôes de "caráter endógeno" frente à internacionalização crescente do continente.

Desse modo, Saraiva (2012) indica que há algumas iniciativas africanas de autonomia decisória, desenvolvimento e sustentabilidade, como a União Africana e a Nova Parceria para o Desenvolvimento da África (NEPAD), que reposicionam o continente. Para o autor, o conceito de Renascimento Africano no contexto atual é mais altruísta e pragmático, diante do utilizado nas nascentes independências africanas dos anos 1960 e 1970.

Frente a esse cenário, nosso objetivo é o de analisar se de fato o conceito de Renascimento Africano contempla uma ressignificação do continente, pois consideramos que se trata de uma importante reflexão sobre a reinserçấo africana na política internacional, visto que demonstra a dificuldade da África em lidar com os velhos desafios, como a instabilidade política e econômica ainda presentes no cenário do continente. Nossa hipótese é a de que o conceito de Renascimento Africano utilizado por analistas como Saraiva $(2008,2015)$ e Diallo (2011), apesar de elevar a perspectiva de que a África se encontra em posição estratégica nas relaçôes internacionais, sendo um conceito fundamental, não expressa de forma suficiente a realidade ainda instável sobre o desenvolvimento econômico, a integraçáo e autonomia decisória do continente.

\section{Desafios dos Estados africanos na pós-descolonização}

A década de 1960 é marcada pelos processos de independência dos Estados africanos, os quais ocorreram dentro de suas especificidades, configurando-se politicamente em 55 países com heterogêneas características políticas, culturais, sociais e econômicas, abordadas muitas vezes como "um problema por resolver", conforme discute Macamo (2013) 
sobre a forma como os estudos africanos constroem o seu objeto. $\mathrm{O}$ autor levanta algumas objeções de ordem epistemológica e metodológica, ressaltando a importância de construçáo de objetos a partir de conceitos e de reformulação das perguntas.

Assim, a nossa pergunta aqui configura-se em: "O conceito de Renascimento Africano expressa um novo momento político para a África?”. Não obstante, o que aqui destacamos como desafios após a descolonização da África está dentro da discussão acerca da África independente, que paulatinamente se insere na nova ordem mundial, com crescente participação nas organizaçóes internacionais e estabelecendo parcerias estratégicas.

Os desafios do continente africano após a descolonização são diversos e não provocam açóes e realizaçóes de uma ruptura completa, pois demandam inovação diplomática e redefinição de relações com as antigas potências (MBOKOLO, 2011; AMIN, 1990). Muitos desses desafios são analisados nos oito volumes da obra História Geral da África, que consiste em um dos projetos editoriais mais importantes da UNESCO nos últimos 30 anos e permite compreender o desenvolvimento histórico dos povos africanos na perspectiva dos próprios africanos, com vasta contribuição intelectual de especialistas.

Nessa senda, alguns dos desafios pós-coloniais da África são: a formação dos Estados nacionais com dirigentes locais ocidentalizados, e, portanto, algumas tensóes são produzidas em torno da identidade nacional da África independente na edificação da nação e formação dos Estados, além da manutenção das estruturas coloniais no aparato militar e no campo econômico. Dessa forma, a África recém-independente busca se inserir no cenário internacional, mas com diversos dilemas internos, frutos do legado colonial.

Visentini (2008) aponta que os desafios e problemas africanos após a descolonização eram imensos e que, mal haviam estabelecido suas inde- pendências, os Estados vivenciavam o contexto da bipolaridade durante a Guerra Fria, tentando estabelecer relaçóes estratégicas. $\mathrm{O}$ autor conclui que:

A adequação da África aos parâmetros da chamada Nova Ordem Mundial, contudo, não significava a solução dos problemas existentes. O fim da bipolaridade e do próprio conflito Leste-Oeste, agravado pelo desmembramento e desaparecimento da Uniáo Soviética em fins de 1991, fez com que o continente africano perdesse sua importância estratégica e capacidade de barganha, ao que se acrescentava a própria perda de importância econômica (VISENTINI, 2008, p. 129).

No contexto de fim da Guerra Fria, o continente africano perde a importância estratégica no cenário internacional. A primeira década pós-Guerra Fria é analisada como um período de crises e de ajustes em diversas regiōes da África. De igual modo, em outras regiōes do globo, há o impacto da onda neoliberal, que expande a exclusão social, o desemprego e a crise (EDMONDSON, 2011).

Diante dos desafios, no início do século XXI, teoriza-se sobre um outro momento político para o continente africano, marcado por soluçóes africanas para problemas africanos, que nos fazem refletir sobre o conceito de Renascimento Africano no intuito de definir ou redefinir um contexto mais assertivo para o comportamento da África no cenário internacional. A partir disso, esboçamos a seguir o debate conceitual do Renascimento Africano e a sua reverberação.

\section{O conceito de Renascimento Africano}

O Renascimento, no contexto europeu, é um conceito da cultura clássica surgido na Itália no século $\mathrm{XV}$, que posiciona o homem como centro de todos os interesses a partir de uma relação entre indivíduo e realidade objetiva (CRUZ, 1999). Por compreender que o Renascimento teve outras 
aplicabilidades históricas, e que, inclusive, problematizavam e subalternizavam as relaçóes com o continente africano durante décadas, destacaremos aqui a concepção, origem e desdobramentos do Renascimento na África.

O conceito de Renascimento Africano emerge como noção pelo antropólogo e historiador senegalês Cheikh Anta Diop, em uma série de ensaios elaborados a partir de 1946 e posteriormente reunidos no livro Towards the African Renaissance: Essays in Culture and Development, 1946-1960. Diante disso, observa-se que esse conceito é apresentado em diversas fases, conforme Diallo (2011) trata, em seu artigo, o histórico do conceito de Renascimento e a relação deste como continente africano, a explanar que:

Portanto, tratando-se do continente africano, após a descoberta dele como berço da humanidade, assistiremos ao seu renascimento em várias fases, tais como o período das independências, principalmente no ano de 1960 , depois tivemos a criação da Organização da Unidade Africana em 1963, num terceiro momento a libertação do líder Nelson Mandela, em 1990 e subsequente fim do apartheid, e por fim a criação da União Africana em 2002 (DIALLO, 2011, p. 93).

Portanto, a conceituação do Renascimento Africano não é recente. Segundo Saraiva (2015, p. 11), "embora pareça um fenômeno do momento, uma criação política passional, uma vontade do hoje, a ideia do renascimento africano tem longa maturação". Como se observa, é um conceito que emerge historicamente a partir da década de 1940 como valorização da realidade africana, sendo influenciado por vários aspectos políticos e filosóficos. A referida conceituação se inicia quase simultaneamente às independências, no final da década de 1950 e 1960.

Não obstante, a renascença da África é apontada como um movimento que define uma nova realidade política. Compreende-se que o Renascimento Africano é um conceito central para o continente e que aparece atrelado aos ideais de unidade, desenvolvimento e inserção internacional, a permear um debate histórico de retomada e iniciativas políticas africanas. Hlophe e Landsberg (1999) destacam duas características dessa renascença. A primeira diz respeito à relação entre esse renascimento e o termo ganense "Sankofa", que significa mover o continente africano em direção a um futuro próspero (prosperidade esta que seria alcançada através da valorização e do resgate do passado africano anterior à invasão europeia). Já a segunda refere-se à importância da interaçáo entre a democracia e o desenvolvimento econômico, o que criaria um cenário estável e favorável ao crescimento econômico, garantindo à África o acesso à economia global.

Para Saraiva (2012, p. 57), "há um outro renascimento, novos consensos, com outras referências culturais, políticas e sociais, com resultantes a serem alcançadas no mundo que vem aî". De fato, verifica-se, nas análises sobre o conceito de Renascimento Africano, os contornos de uma ideia de renovação política, mas Saraiva (2012) enfatiza a importância de preservar a capacidade crítica em relação ao presente e aos caminhos para o futuro e trata disso citando a obra de Paulo Farias (2007), que evidencia o risco de mitificar o passado com o discurso de renascença, embora busque-se exatamente o contrário.

O conceito de Renascimento Africano é muito presente nos projetos políticos do continente, como a União Africana, criada em 2002, que traçou em 2013 as sete metas da agenda 2063 com base nas concepçóes de Renascimento Africano e Pan-Africanismo, trazendo-os como lemas (NETO, 2017). Importante enfatizar que, ao lado do Renascimento Africano, tem estado o Pan-Africanismo como ideias fundamentais para o pensamento polí- 
tico africano, sobretudo no âmbito da União Africana, embora ambos não devam ser confundidos ${ }^{2}$. O Renascimento Africano é construído como um conceito próprio da África, que não imita o Renascimento Europeu, por exemplo.

Ao observarmos a relevância do Renascimento Africano junto a outros conceitos, como o de Pan-Africanismo, há perspectivas como a de Otávio (2013), que trata sobre esse tema e denota que ambos os conceitos buscam romper com o subdesenvolvimento e fortalecem a tentativa de integração continental, distinguindo que o Renascimento Africano é consubstanciado na própria dinâmica da Nova Parceria Econômica para o Desenvolvimento Africano (NEPAD), e, portanto, é visto como muito entusiasmo pelas potências ocidentais por pautar o neoliberalismo e os moldes da globalização. O autor argumenta que, sendo a NEPAD um fruto do Renascimento Africano, a estratégia nesse contexto não é exatamente contestar o desenvolvimento com o neoliberalismo vigente, mas apontar a responsabilidade mútua como melhor estratégia de inserção econômica.

Nesse sentido, nosso argumento central é destacar que a noção de Renascimento Africano, ao servir aos interesses da comunidade internacional, ressalta ainda mais os desafios enfrentados pelos Africanos, uma vez que as críticas à NEPAD são, na verdade, críticas aos modelos de desenvolvimento adotados pelo continente no século XXI.

Compreende-se que o Renascimento Africano, retomado como um conceito "[...] mais pragmático e altruísta no século XXI" (SARAIVA, 2015, p. 13), mesmo impulsionando a ideia de crescimento econômico, parece revelar os desafios que ainda permeiam as relaçóes internacionais da África, as quais tentaremos observar a seguir.

2 Maiores informações estão disponíveis em PHEKO, 2014.

\section{Renascimento Africano no século XXI: Velhos desafios sobre a inserção internacional da África}

O discurso sobre o Renascimento Africano envolve a elucidação de que "novos arranjos entre as elites locais e internacionais trazem a autonomia decisória e o desenvolvimento sustentável ao continente" (SARAIVA, 2015, p. 59). Há, de fato, algumas reflexốes que trazem entusiasmo sobre a inserção da África nas próximas décadas, o que aqui esboçamos como velhos desafios, os quais apontamos como: Integração, NEPAD e Desenvolvimento.

Um dos desafios diz respeito à relação entre o conceito de Renascimento Africano e a perspectiva de integração do continente africano, pois a ideia do Renascimento pressupóe o desafio da consolidação da integração do continente, tendo em vista que o debate da unidade e da integração é travado desde os anos 1960.

Diallo (2011, p. 93) expóe que, "para os países em desenvolvimento, a integração regional não é um fim em si, mas um capítulo de uma estratégia mais ampla para promover um crescimento equitativo". As estratégias de integração econômica seguem ainda um formato similar. Como apontam Luigi e Pennaforte (2010), a maioria dos processos de integração africanos está no estágio de integração de Mercado Comum, como a Comunidade dos Estados Sahel-Saarianos (CEN-SAD), o Mercado Comum da África Oriental e Austral (COMESA), a Comunidade da África Oriental (EAC), a Comunidade Econômica dos Estados Centro-Africanos (ECCAS ou CEEAC), a Comunidade Econômica dos Estados da África Ocidental (CEDEAO ou ECOWAS), a Autoridade Intergovernamental para o Desenvolvimento (IGAD), a Comunidade para o Desenvolvimento da África Austral (SADC) e a União Árabe do Magrebe (UAM). Ao listar os blocos existentes no continente africano, os autores ponderam: 
Os mesmos países fazem parte de mais de um bloco, o que torna determinadas políticas ineficientes, dada a incapacidade dessas nações de atenderem a políticas distintas de integração. Outro problema é o fraco apoio nacional aos programas de integração regional, na maior parte das vezes, provocado por um desconhecimento do que sejam de fato os compromissos assumidos por cada país membro quando de uma associação a um bloco (LUIGI; PENNAFORTE, 2010, p. 173).

Sob o viés econômico, observam-se alguns importantes avanços nos processos de integração que têm sustentado o argumento de um momento de maior projeçáo internacional do continente no cenário internacional no século XXI. Todavia, percebemos que há dificuldades no tocante à integração econômica e política dos países africanos, dadas as suas heterogêneas formaçóes e interesses, o que apontamos como um dos velhos desafios, uma vez que o discurso do Renascimento Africano permanece como um ideal a ser atingido, constituindo-se este como um desafio para a África construir o seu próprio destino.

O período em que a África vislumbra uma integração global e traça alguns caminhos para esse intuito é sinônimo de Renascimento Africano, pois denota um novo perfil de desenvolvimento africano, como o que define Saraiva (2012, p. 56), de “otimismo cauteloso". Ademais, outro desafio que apontamos refere-se à Nova Parceria para o Desenvolvimento Africano (NEPAD), lançada em 2001, a qual é vista de forma crítica por reproduzir um modelo de desenvolvimento aos países africanos frente à Globalização. Fonseca (2015) elucida que o continente africano mergulha numa lógica neoliberal de reproduzir modelos que só aumentam a dívida externa e a instabilidade social e econômica.

$\mathrm{O}$ autor também considera que a maior parte dos Estados africanos não conseguiu superar sua herança colonial em termos de estrutura econômico-produtiva, algo que corroboramos como um desafio histórico para o continente. Apesar do ineditismo em oportunidades, o mundo da economia globalizada encontra-se transformado quando comparado aos moldes de economia primário-exportadora de alguns países.

Para tanto, além do desafio da integraçáo, outro velho desafio que aqui queremos denotar é o do "Desenvolvimento", pois o conceito de Renascimento Africano é pensado a partir da dinâmica do desenvolvimento refletido para a África, considerando a afirmação de Macuane (2005) de que há uma tendência quase fatalista de o continente ser o alvo preferido de experimentos de receitas de modelos de desenvolvimento.

A criação da Nova Parceria para o Desenvolvimento da África - NEPAD sem dúvida é um grande passo nessa direcção. Contudo, não se pode esperar da mesma que seja a panaceia e a tábua de salvação para todos os problemas de subdesenvolvimento e especialmente de pobreza do continente, sob o risco dela mesma transformar-se em mais um instrumento de propagaçáo dos preceitos de um modelo de desenvolvimento padronizado, prescritivo e desfocado da realidade (MACUANE, 2005, p. 9).

Vale salientar que o desenvolvimento africano é abordado pelo autor como um "Desenvolvimento à la carte" pelos dilemas e entraves de adequar-se a modelos pré-estabelecidos que não dialogam com as realidades africanas e que têm exigido alternativas de desenvolvimento endógenas. Como podemos observar, o conceito de Renascimento Africano endossa a visão de que o continente cria um momento positivo de inserção internacional no século XXI, apesar do enfrentamento de velhas questóes.

Cabe lembrar que a integração e o desenvolvimento vêm gerando, simultaneamente, essa expectativa de responsabilidade para o futuro. Ademais, o conceito de Renascimento Africano é algo que retorna para dar fôlego aos interesses africanos que estáo se pautando nos âmbitos da Cooperação Sul-Sul e de uma internacionalização econômica do capitalismo. 
A revisão do conceito de Renascimento Africano é relevante para percebermos os discursos que envolvem a África em busca dos seus objetivos, ao se entender que os desafios são os mesmos, mas as estratégias estão sendo repensadas neste início de século, ainda que "a conexão África-China [...] [tenha] todas as condiçóes de ser a mais duradoura sobre todos os demais intentos de qualquer unidade estatal, mesmo dos Estados Unidos, de estabelecer bases de cooperação ativa como o renascimento africano" (SARAIVA, 2012, p. 63).

Nesse aspecto, ao tratar dos velhos desafios para a África, a nossa crítica se dá conforme aponta Saraiva (2012, p. 65), ao comentar que o importante é observar se o "[...] futuro estratégico do continente não está sendo traçado de fora para dentro". Outro aspecto relevante é que o uso do conceito de Renascimento Africano não recrie uma realidade vista de fora e sem reenquadrar a realidade da África na contemporaneidade. É preciso mais do que mobilizar conceitos.

\section{Considerações Finais}

Ao discutirmos sobre o continente africano e os desafios pós-coloniais, compreendemos que eles estáo fundamentados na preocupação da inserção internacional da África. Alguns conceitos são trazidos para traduzir o novo momento africano, como o Pan-Africanismo. Um dos mais importantes dentre eles é o de Renascimento Africano, sendo necessário um aprofundamento sobre a ressignificação dada, pois há o risco de sobrepor o otimismo à realidade, tendo em vista que encontramos ainda os desafios da integração e do desenvolvimento que não sejam pautados em reprodução de modelos ou de um "desenvolvimento à la carte"

Nota-se que os desafios sobre a inserção internacional da África no século XXI extrapolam a conceituação do Renascimento, pois o surgimento da
Uniāo Africana e da NEPAD geram um novo ciclo, além de apontarem desafios que não são recentes e estâo no entorno da Integração e o do Desenvolvimento, com vistas a alcançar maior estabilidade política e econômica.

Todavia, as evoluçôes endógenas se realizam a partir de ideologias políticas próprias. Nesse intuito, o Renascimento Africano cumpre parte do seu papel de apresentar a África renascida em um processo cada vez maior de inserção internacional, com crescimento econômico que se expande, mas que nâo se reflete de forma suficiente diante dos dilemas surgidos desde a descolonização no que se refere às estratégias da África.

Consideramos que a ênfase conferida ao Renascimento Africano serve às interpretaçôes mais esperançosas sobre o futuro do continente, as quais devem passar por críticas mais profundas, uma vez que se trata, ao que parece, de um conceito insatisfatório ao ignorar os fatores internos no que tange ao desenvolvimento econômico próprio, uma integração mais consolidada e um cenário mais estável e favorável para os Estados Africanos nas Relações Internacionais.

\section{Referências Bibliográficas}

AMIN, S. Para uma estratégia de desenvolvimento autocentrado na África. África América Latina, cadernos: Revista de análises Sul-Norte para uma cooperação solidária, n. 1, p. 27-38, 1990. CRUZ, Cláudia Helena da. Repensando o tema do Renascimento: reflexóes sobre o ensino de História. 1999, 95 f. Trabalho de Conclusão de Curso. Bacharelado em História junto ao Departamento de História da Universidade Federal de Uberlândia, Uberlândia, 1999.

DIALLO, A. O. Renascimento Africano e desenvolvimento. Revista Conjuntura Austral, v. 2, n. 6, jun./jul. 2011. Disponível em: <https://seer.ufrgs.br/ConjunturaAustral/article/ view/20575>. Acesso em 29 de Abril. 2019.

EDMONDSON, L A. África em vias de desenvolvimento. In: MAZRUI, Ali A.; WONDJI, Christophe. (Eds). História Geral da África: v. VIII: África sob dominação colonial. 1880-1935. São Paulo: Cortez; Brasília: UNESCO, p. 1003 1042, 2011. 
FARIAS, P. Tombuctu, a África do Sul e o idioma de renascença africana. Seminário preparatório dos temas africanos para a II CNPEPI, 2 e 3 de março de 2007.

FONSECA, D. F. A África entre a desesperança neoliberal e o "Renascimento Africano": dívida externa, pobreza e desenvolvimento. Revista África e africanidades, ano 8, n. 20, jul. 2015.

HLOPHE, D.; LANDSBERG, C. O Renascimento Africano como uma moderna estratégia de Política Externa Sul-Africana. Paris: CERI, 1999.

HUGON, P. "Problemas e desafios internos" e "A África e a sociedade internacional". In: HUGON, P. Geopolítica da África. Rio de Janeiro: FGV, p. 80-164, 2010.

LUIGI, R.; PENNAFORTE, C. A integraçáo global do continente africano. In: LUIGI, R.; PENNAFORTE, C. (Orgs.). Perspectivas Geopolíticas: uma abordagem contemporânea. Rio de Janeiro: CENEGRI, p. 163-184 (v. 1), 2010. Disponível em: <https://www.researchgate.net/publication/321082551_A_Integracao_Global_do_Continente_Africano>. Acesso em 08 mai. 2019.

MACAMO, E. Respostas sem perguntas, ou: porque África não é um problema por resolver. In: SEMINÁRIO INTERNACIONAL SOBRE CIÊNCIAS SOCIAIS E DESENVOLVIMENTO EM ÁFRICA, 2, 2013, Lisboa. Anais... Lisboa: Painel V: Promoção da Ciência e Desenvolvimento, p. 255-254, 2013. Disponível em: <https://pascal.iseg.ulisboa.pt/ - cesa/index.php/ en/menupublicacoes/e-book/502>. Acesso em: 10 mai. 2019.

MACUANE, J. J. Os paradoxos do desenvolvimento à La Carte. Conferência apresentada na XI Assembleia Geral da CODERSIA, Maputo, 6 a 10 de dezembro de 2005. Disponível em: <www.codesria.org/Links/conferences/general.../port/ GA_prog_port.pdf>. Acesso em: 10 mai. 2019.
MBOKOLO, E. África Negra: História e Civilizaçôes (Tomo II). Salvador: EDUFBA/Casa das Áfricas, p. 630-653, 2011.

NETO, S. Líder da União Africana critica desigualdades na ONU: "Nós não somos fantasmas". Alma Preta, Editoriais, 18 jan. 2017. Disponível em: <https://almapreta.com/editorias/ mama-africa/lider-da-uniao-africana-critica-desigualdade-na-onu-nos-nao-somos-fantasmas>. Acesso em: 11 mai. 2019.

OTÁVIO, A. Entre o pan-africanismo e o African Renaissance: A busca pelo desenvolvimento em um mundo em transformaçáo. Conjuntura Internacional, Belo Horizonte, v. 10, n. 3, p. 84-97, 2o sem., 2013.

PHEKO, M. De qual Renascimento Africano estamos falando? Pambazuka News, Governança, 16 fev. 2014. Disponível em: $<$ https://www.pambazuka.org/pt/governance/de-qual-renascimento-africano-estamos-falando >. Acesso em: 11 mai. 2019.

SARAIVA, J. F. S. A África no ordenamento internacional do século XXI: uma interpretação brasileira. Anos 90, Porto Alegre, v. 15, n. 27, p. 75-106, jul. 2008.

SARAIVA, J. F. S. A África no século XXI: um ensaio acadêmico. Brasília: FUNAG, 2015. Disponível em: <http://funag. gov.br/biblioteca/download/1121_a_africa_no_seculo_xxi_ um_ensaio_academico.pdf.> Acesso em 20 de Abril. 2019.

SARAIVA, J. F. S. África parceira do Brasil atlântico: relaçôes internacionais do Brasil e da África o início do século XXI. Belo Horizonte: Fino Traço, 2012.

VISENTINI, P. F. Independência, marginalização e reafirmação da África (1957-2007). In: MACEDO, J.R. (Org.). Desvendando a história da África. Porto Alegre: Editora da UFRGS, 2008. Disponível em: <http://books.scielo.org/id/yf4cf/ pdf/macedo-9788538603832.pdf>. Acesso em: 10 mai. 2019. 